\title{
Influence of pyrolysis temperature and production unit on formation of selected PAHs, oxy-PAHs, N-PACs, PCDDs, and PCDFs in biochar-a screening study
}

\author{
Eva Weidemann ${ }^{1} \cdot$ Wolfram Buss $^{2} \cdot$ Mar Edo $^{1} \cdot$ Ondřej Mašek $^{2} \cdot$ Stina Jansson $^{1}$
}

Received: 3 May 2017 / Accepted: 24 October 2017 /Published online: 8 November 2017

(C) The Author(s) 2017. This article is an open access publication

\begin{abstract}
The influence of reactor type and operating conditions of the pyrolysis unit on the final concentration of toxic contaminants in biochar remains unclear. Therefore, we determined the concentrations of polycyclic aromatic hydrocarbons (PAHs), oxygenated polycyclic aromatic hydrocarbons (oxy-PAHs), nitrogen-containing polycyclic aromatic compounds (N-PACs), polychlorinated dibenzo-p-dioxins (PCDDs), and dibenzofurans (PCDFs) in biochars produced from three different feedstocks (softwood, wheat straw, and anaerobic digestate). Different scaled pyrolysis units (one batch and two continuous units) at two different temperatures $\left(550\right.$ and $\left.700{ }^{\circ} \mathrm{C}\right)$ were considered. The results revealed that the type of biomass had a significant influence on the PAH, oxy-PAH, and N-PAC content of the biochars. The configuration and type of the pyrolysis unit influenced only the wheat straw pyrolyzed at $550{ }^{\circ} \mathrm{C}$. PCDDs and PCDFs occurred at very low levels in the biochars. In terms of PAH, PCDD, and PCDF content, the biochars assessed in this study represent a low risk to the environment, regardless of the temperature and type and size of the pyrolysis unit.
\end{abstract}

Keywords Polychlorinated dibenzo- $p$-dioxin . Polychlorinated dibenzofuran $\cdot$ Polycyclic aromatic hydrocarbons $\cdot$ Oxygenated polycyclic aromatic

Responsible editor: Roland Kallenborn

Stina Jansson

stina.jansson@umu.se

1 Department of Chemistry, Umeå University, SE-901 87 Umeå, Sweden

2 UK Biochar Research Centre, School of GeoSciences, University of Edinburgh, Edinburgh, UK hydrocarbons $\cdot$ Nitrogen-containing polycyclic aromatic compounds

\section{Introduction}

During pyrolysis, materials undergo thermochemical decomposition at temperatures above $300{ }^{\circ} \mathrm{C}$ in an oxygen-limited environment. The yield and chemical composition of the resulting pyrolysis products vary with the characteristics of the feedstock and the process variables, e.g., heating rate and residence time of the process (Mohan et al. 2006; Zhao et al. 2013). To date, the liquid and gas fraction has been the most analyzed pyrolysis product. However, biochar from lignocellulosic biomass has gained significant attention due to its properties and potential use in environmental and agricultural applications (e.g., as soil amendment and replacement for or supplement to activated carbon (Lehman and Joseph 2009)).

Thermal decomposition of biomass yields a complex mixture of condensable hydrocarbons, i.e., tar, which consists of single- to five-ring aromatics, phenolic compounds, and complex polycyclic aromatic hydrocarbons (PAHs) (Wolfesberger et al. 2009). The tar-like products are highly branched at moderate temperatures $\left(\sim 500^{\circ} \mathrm{C}\right)$ (Pakdel and Roy 1991), but (in general) highly condensed and less oxygenated at high temperatures $\left(>700{ }^{\circ} \mathrm{C}\right)$ (Elliott 1986; Baker and Elliott 1986). Oxygenated-PAHs (oxy-PAHs) and nitrogen-containing heterocyclic polycyclic aromatic compounds (N-PACs), which typically occur as PAH co-pollutants in soils and groundwater (Lundstedt et al. 2003; Arp et al. 2014), display similar toxicity to PAHs (Andersson and Achten 2015). Therefore, oxyPAHs should be considered for inclusion in biochar regulations. Oxy-PAHs may form through either biological, chemical or photo-oxidation (Andersson and Achten 2015), or catalytic transformation of PAHs (Nielsen et al. 1999), whereas 
N-PACs form via pyrolysis of lignocellulose materials and sewage (Britt et al. 2002). N-PACs have been reported from the pyrolysis of sewage sludge (Fullana et al. 2003). During thermochemical processes, PAHs (Weber et al. 2001) and oxyPAHs (Hajizadeh et al. 2011) may also act as precursors for the formation of chlorinated aromatics, such as polychlorinated dibenzo-p-dioxins (PCDDs) and polychlorinated dibenzofurans (PCDFs).

Biochar intended for soil application must fulfill certain property- and composition-related requirements, to prevent harm to the ecosystem (Buss and Mašek 2014). Therefore, several guidelines with suggested threshold values for contaminants (including PAHs, PCDDs, or PCDFs) in biochar have been established, and the importance of contaminant analysis has been emphasized (British Biochar Foundation 2014; International Biochar Initiative 2015; European Biochar Foundation 2016).

Biochars with low concentration of contaminants may be achieved by selecting suitable feedstocks and controlling the operating conditions in the pyrolysis unit. Therefore, knowledge of the variation in different process variables associated with different pyrolysis units is essential for producing highquality biochar. However, a relationship between the pyrolysis temperature and the concentration of $\mathrm{PAH}$ in biochar remains elusive (Freddo et al. 2012; Hale et al. 2012; Kloss et al. 2012; Devi and Saroha 2015). Buss et al. (2016a) have attributed this to a simultaneous increase in PAH formation and evaporation from the biochar with increasing temperature. The influence of the scale, reactor type, and configuration of the pyrolysis unit on the PAH concentration of the biochar remains unclear. In addition, the concentration of chlorinated organics in biochar has rarely been assessed (Hale et al. 2012; Wiedner et al. 2013), and to the best of our knowledge, the concentrations of oxy-PAH and N-PAC in biochars have yet to be reported.

In this study, we evaluate organic contaminants (PCDD, PCDF, PAH, oxy-PAH, and N-PAC) found in biochars from different biomass materials treated in different types of pyrolysis units. Three different feedstocks (softwood pellets, wheat straw pellets, and anaerobic digestate) were pyrolyzed at two different temperatures $\left(550\right.$ and $\left.700{ }^{\circ} \mathrm{C}\right)$, using three pyrolysis setups (one batch and two continuous units) of different scales.

\section{Materials and methods}

\section{Feedstocks}

The biochars were produced from three different types of biomass: commercial softwood (pine and spruce) pellets (Premium Puffin, Puffin Pellets), commercial wheat straw pellets (Agripellets Ltd.), and anaerobically digested sewage sludge (AD) from water-treatment works. The characterization of these feedstocks, proximate and ultimate analysis, are shown in Table 1.

\section{Pyrolysis experiments}

The pyrolysis experiments were conducted in three different pyrolysis reactors (one batch reactor and two continuous reactors) located at the UK Biochar Research Centre (UKBRC), University of Edinburgh. Key characteristics of the units are presented in Table 2 and further details can be found in the referenced articles.

An overview of the performed pyrolysis experiments and the collected samples is provided in Table 3 . In the two continuous reactors (stages II (Buss et al. 2016b) and III (Buss and Mašek 2014)), mean residence times of 20 min were applied for all materials. The residence time was estimated by establishing first the temperature profile of the biomass/char bed along the rotary kiln reactor (stage III, Table 2) as well as the residence time distribution of particles in the reactor. Based on this information, the corresponding heating rate experienced by particles in the reactor and their residence time at the peak temperature were calculated. Therefore, while the mean residence time of particles in continuous reactor was $20 \mathrm{~min}$, the residence time at peak temperature was only between 5 and $10 \mathrm{~min}$, depending on the material used. Thus, obtained parameters were then used as settings in the batch reactor to reproduce the conditions in the continuous pyrolysis unit as closely as possible. In the stage I reactor (Crombie et al. 2013), the retention time at the highest treatment temperature was adapted to reflect the retention times in the heated areas of the furnace of the continuous reactors. Therefore, softwood was exposed for $10 \mathrm{~min}$ (each) to temperatures of 550 and $700{ }^{\circ} \mathrm{C}$, whereas wheat straw was exposed for 5 and $6 \mathrm{~min}$, respectively.

\section{Sample extraction and cleanup}

We determined the fraction of 16 EPA priority PAHs (US EPA 2015), 11 oxy-PAHs (Arp et al. 2014; Andersson and Achten 2015), and 4 N-PACs (Arp et al. 2014), PCDDs, and PCDFs (homolog sums and $\mathrm{WHO}_{2005}$-TEQ) (Van den Berg et al. 2006)) occurring in biochars and liquid samples. The target PAHs, oxy-PAHs, and N-PACs are listed in Table 4.

The chars were extracted, at $150{ }^{\circ} \mathrm{C}$, via pressurized liquid extraction (Dionex 350, Thermo Fisher Scientific, Waltham, USA) using toluene of analytical grade quality (Fluka, $\geq 99.7 \%$ ), following the procedure outlined by Gao et al. (2015). The liquid fraction was extracted via liquid/liquid extraction using n-hexane. For PCDD and PCDF analysis, the extracts were all cleaned up using a multi-layer silica column followed by fractionation with an AX-21 carbon/celite column (see Liljelind et al. (2003) for further details of the method). For analysis of PAHs, oxy-PAHs, and N-PACs in the char 
Table 1 Proximate and ultimate analysis for the studied feedstocks

\begin{tabular}{lllll}
\hline & Unit & Softwood & Wheat straw & Anaerobic digestate \\
\hline Moisture & wt\% (a.r.) & $6.71 \pm 0.03(5)$ & $7.22 \pm 0.22(5)$ & $5.72 \pm 0.27(6)$ \\
Volatiles & wt\% (d.b.) & $83.6 \pm 0.4(5)$ & $76.3 \pm 0.5(5)$ & $64.6 \pm 0.4(6)$ \\
Fixed carbon & wt\% (d.b.) & $14.4 \pm 0.4(5)$ & $16.6 \pm 1.1(5)$ & $7.7 \pm 0.3(6)$ \\
Ash & wt\% (d.b.) & $1.1 \pm 0.1(5)$ & $7.0 \pm 0.3(5)$ & $27.8 \pm 0.5(6)$ \\
C & wt\% (d.b.) & $49.9(2)$ & $45.2(2)$ & $38.0(2)$ \\
H & wt\% (d.b.) & $6.6(2)$ & $5.4(2)$ & $0.60(2)$ \\
$\mathrm{N}$ & wt\% (d.b.) & $<0.10(2)$ & $0.58(2)$ & $4.29(2)$ \\
\hline
\end{tabular}

$w t$, weight; a.r., as received; $d . b$. , dry basis; $n$, number of replicates samples, cleanup was conducted using open columns containing $5 \mathrm{~g} \mathrm{KOH}$-silica, eluted with dichloromethane. The clean extracts were concentrated to $\sim 1 \mathrm{~mL}$ of toluene. The liquid samples were cleaned via the same procedure, using n-hexane (rather than dichloromethane) as the eluent. Further details of the method for PAH, oxy-PAH, and N-PAC analysis are provided elsewhere (Arp et al. 2014). All samples were single samples.

\section{Instrumental analysis}

The analyses were all performed on a GC-HRMS-HewlettPackard 5890 gas chromatograph (Agilent Technology, Santa Clara, USA) coupled to an Autospec Ultima Mass Spectrometer (Waters Corporation, Milford, USA), using a DB5 column (60 m length, $0.32 \mathrm{~mm}$ internal diameter, $25 \mu \mathrm{m}$ film thickness) (Agilent Technology, Santa Clara, USA). The main purpose of using HRMS was to make it possible to separate oxy-PAHs from PAHs, and the method used was previously described by Arp et al. (2014). The mass spectrometer was operated in electron impact ionization/ selected ion-monitoring mode and analytes were quantified using the isotope dilution technique. PAHs, oxy-PAHs, and N-PACs were identified by comparing retention times to quantification congeners in the reference standard, while PCDD and PCDF were compared with published GC-MS chromatograms (Ryan et al. 1991; Bacher et al. 1992).

\section{QA/QC}

All laboratory work was performed using validated methods, and laboratory blanks were extracted with the samples and treated as samples (i.e., single samples) throughout the cleanup process. The reported concentrations (signal-to-noise ratio: 10) were all higher than the limit of quantification (LOQ). For all reported concentrations, blank concentrations were below five times sample concentrations. Due to this cutoff, acenaphthylene was removed from the reported results due to analytical uncertainties.

\section{Results and discussion}

\section{PAHs in the biochars}

The total PAH concentrations measured in the biochars varied considerably, from 0.82 to $19.6 \mu \mathrm{g} \mathrm{g}_{\text {biochar }}{ }^{-1}$, and seemed to be largely influenced by the feedstock type. This is particularly striking for concentrations in the three biochars produced at $550{ }^{\circ} \mathrm{C}$ (Fig. 1). For the same pyrolysis unit, the PAH concentrations of the wheat straw-derived biochars were (in some cases) almost seven times higher than those obtained from the softwood feedstock. The PAHs in biochars from all three feedstocks consisted mainly of two- and three-ring species, regardless of the pyrolysis temperature and unit scale. Furthermore, multi-ringed species, i.e., four- to six-ringed PAHs, occurred more abundantly in the wheat straw-derived biochar than in the other feedstocks. However, consistent with a previous study (Keiluweit et al. 2012), wheat straw-derived biochars produced at $700{ }^{\circ} \mathrm{C}$ contained higher concentrations of PAHs than those produced at $550{ }^{\circ} \mathrm{C}$. The unit size had a substantial impact on PAH formation only for wheat straw pyrolyzed at $550{ }^{\circ} \mathrm{C}$, where $\mathrm{PAH}$ formation was positively correlated with the unit size.

The International Biochar Initiative (IBI) guidelines have established threshold values, 6 and $300 \mu \mathrm{g} \mathrm{g}$ biochar $^{-1}$, lower

Table 2 Characteristics of the pyrolysis reactors used in this study

\begin{tabular}{lllllll}
\hline Name & Operation mode & Temperature & Type of heating & Capacity & Carrier gas flow & Ref. \\
\hline Stage I & Batch & Max $\sim 1200{ }^{\circ} \mathrm{C}$ & Infrared furnace & $30-50 \mathrm{~g} \mathrm{run}^{-1}$ & $0.3 \mathrm{~L} \mathrm{~min}^{-1}$ & Crombie et al. 2013 \\
Stage II & Continuous - auger & $\operatorname{Max} \sim 850^{\circ} \mathrm{C}$ & Electric split-tube furnace & $500 \mathrm{~g} \mathrm{~h}^{-1}$ & $1 \mathrm{~L} \mathrm{~min}^{-1}$ & Buss et al. 2016-b \\
Stage III & Continuous - rotary kiln & $\operatorname{Max} \sim 850^{\circ} \mathrm{C}$ & Set of electric heaters & $30-50 \mathrm{~kg} \mathrm{~h}^{-1}$ & $10 \mathrm{~min}^{-1}$ & Buss et al. 2014 \\
\hline
\end{tabular}


Table 3 Overview of pyrolysis experiments. X denotes the samples that were analyzed for contaminants. In addition, the product yields for the stage I unit are shown with the number of replicates in parentheses

\begin{tabular}{|c|c|c|c|c|c|c|c|c|c|}
\hline \multirow[t]{2}{*}{ Feedstock } & & \multirow[t]{2}{*}{$550{ }^{\circ} \mathrm{C}$} & \multicolumn{3}{|l|}{ Stage I } & \multicolumn{2}{|l|}{ Stage II } & \multicolumn{2}{|c|}{ Stage III } \\
\hline & & & $\begin{array}{l}\text { Yield (\%) } \\
550{ }^{\circ} \mathrm{C}\end{array}$ & $700{ }^{\circ} \mathrm{C}$ & $\begin{array}{l}\text { Yield } \\
(\%) 700{ }^{\circ} \mathrm{C}\end{array}$ & $550^{\circ} \mathrm{C}$ & $700{ }^{\circ} \mathrm{C}$ & $550{ }^{\circ} \mathrm{C}$ & $700{ }^{\circ} \mathrm{C}$ \\
\hline \multirow[t]{3}{*}{ Softwood } & Biochar & $\mathrm{X}$ & $21 \pm 1.1(4)$ & $\mathrm{X}$ & $19 \pm 0.5(4)$ & $\mathrm{X}$ & $\mathrm{X}$ & $\mathrm{X}$ & $\mathrm{X}$ \\
\hline & Liquid & $\mathrm{X}$ & $46 \pm 1.1$ & $\mathrm{X}$ & $45 \pm 0.9$ & & & & \\
\hline & Gas & & $33 \pm 2.1$ & & $36 \pm 0.8$ & & & & \\
\hline \multirow[t]{3}{*}{ Wheat straw } & Biochar & $\mathrm{X}$ & $25 \pm 0.5(3)$ & $X$ & $23 \pm 0.8(3)$ & $\mathrm{X}$ & $\mathrm{X}$ & $\mathrm{X}$ & $\mathrm{X}$ \\
\hline & Liquid & $\mathrm{X}$ & $44 \pm 0.3$ & $\mathrm{X}$ & $44 \pm 0.8$ & & & & \\
\hline & Gas & & $31 \pm 0.7$ & & $33 \pm 0.8$ & & & & \\
\hline \multirow[t]{3}{*}{ Anaerobic digestate } & Biochar & $\mathrm{X}$ & $25 \pm 1.5(7)$ & & & & & & \\
\hline & Liquid & $\mathrm{X}$ & $49 \pm 1.3$ & & & & & & \\
\hline & Gas & & $26 \pm 1.2$ & & & & & & \\
\hline
\end{tabular}

and upper limit, respectively, for the total PAH concentration of biochar (see Fig. 1) (International Biochar Initiative 2015). The PAH concentrations of the softwood-derived biochars were all less than the lower limit $\left(6 \mu \mathrm{g} \mathrm{g} \mathrm{g}_{\text {biochar }}{ }^{-1}\right)$, regardless of the pyrolysis temperature and the type and size of the unit. All biochars produced in this study meet the IBI PAH standards, and are thereby considered safe for use as soil amendments; softwood yielded the biochar with the lowest potential risk for PAH-related effects.

\section{Oxygenated-PAHs and N-PACs in the biochars}

Oxy-PAHs and N-PACs occurred at detectable levels in all biochars, but the corresponding concentrations were lower than those of the PAHs (Fig. 2). The total oxy-PAH and N-
PAC concentrations ranged from 34 to $3100 \mathrm{ng} \mathrm{g}_{\text {biochar }}{ }^{-1}$ and 0.4 to $477 \mathrm{ng}$ g biochar $^{-1}$, respectively. The oxy-PAHs and N-PACs consisted mainly of three-ringed species, and slightly higher concentrations of the multi-ringed oxy-PAH species were generated during wheat straw pyrolysis than during softwood pyrolysis. As in the case of PAHs, compared with the pyrolysis reactor size the feedstock exerted a larger influence on oxy-PAH formation. Furthermore, the reactor size had a substantial impact only on the oxy-PAH concentration in the biochar generated from wheat straw pyrolyzed at $550{ }^{\circ} \mathrm{C}$. The highest concentration of oxyPAH, which was more than 18 times higher and almost 6 times higher than those of softwood and wheat straw, respectively, was generated during stage 1 pyrolysis (at $550{ }^{\circ} \mathrm{C}$ ) of anaerobic digestate. In this case, the elevated
Table 4 List of analyzed PAH, oxy-PAH, and N-PAC and the number of aromatic rings $\left(\mathrm{n}_{\mathrm{Ar}}\right)$ in each structure

\begin{tabular}{|c|c|c|c|c|c|}
\hline PAH & $\mathrm{n}_{\mathrm{Ar}}$ & Oxy-PAH & $\mathrm{n}_{\mathrm{Ar}}$ & N-PAC & $\mathrm{n}_{\mathrm{Ar}}$ \\
\hline Naphthalene & 2 & 1-Indanone & 2 & Quinoline & 2 \\
\hline $\begin{array}{l}\text { Acenaphthylene } \\
\text { Acenaphthene }\end{array}$ & 3 & $\begin{array}{l}\text { 1-Acenaphthenone } \\
\text { 9-Fluorenone }\end{array}$ & 3 & $\begin{array}{l}\text { Benzo[h]quinoline } \\
\text { Acridine }\end{array}$ & 3 \\
\hline $\begin{array}{l}\text { Fluorene } \\
\text { Phenanthrene }\end{array}$ & & $\begin{array}{l}\text { Anthracene-9,10-dione } \\
\text { 2- Methylanthracene-9,10-dione }\end{array}$ & & Carbazole & \\
\hline $\begin{array}{l}\text { Anthracene } \\
\text { Fluoranthene }\end{array}$ & 4 & $\begin{array}{l}\text { Cyclopentaphenanthrenone } \\
\text { Benzo[a]fluorenone }\end{array}$ & 4 & & \\
\hline Pyrene & & Benz[de]anthracen-7-one & & & \\
\hline Benzo[a]anthracene & & Benz[a]anthracene-7,12-dione & & & \\
\hline Chrysene & & Naphthacene-5,12-dione & & & \\
\hline $\begin{array}{l}\text { Benzo[b]fluoranthene } \\
\text { Benzo[k]fluoranthene }\end{array}$ & 5 & Benzo[cd]pyren-6-one & 5 & & \\
\hline \multicolumn{6}{|l|}{ Benzo[a]pyrene } \\
\hline \multicolumn{6}{|l|}{ Dibenz[ah]anthracene } \\
\hline $\begin{array}{l}\text { Indeno[cd]pyrene } \\
\text { Benzo[ghi]perylene }\end{array}$ & 6 & & & & \\
\hline
\end{tabular}

$\mathrm{n}_{\mathrm{Ar}}$ : number of aromatic rings in each structure 
Fig. 1 Total concentration and distribution of different-sized PAHs (numbers of rings) in each biochar. SI-SIII: size of the pyrolysis equipment (stage I, stage II, and stage III, respectively) and AD: anaerobic digestate. Red dashed line represents the range of lower-limit threshold values (set by IBI (International Biochar Initiative 2015)) for PAHs in biochar used in soil

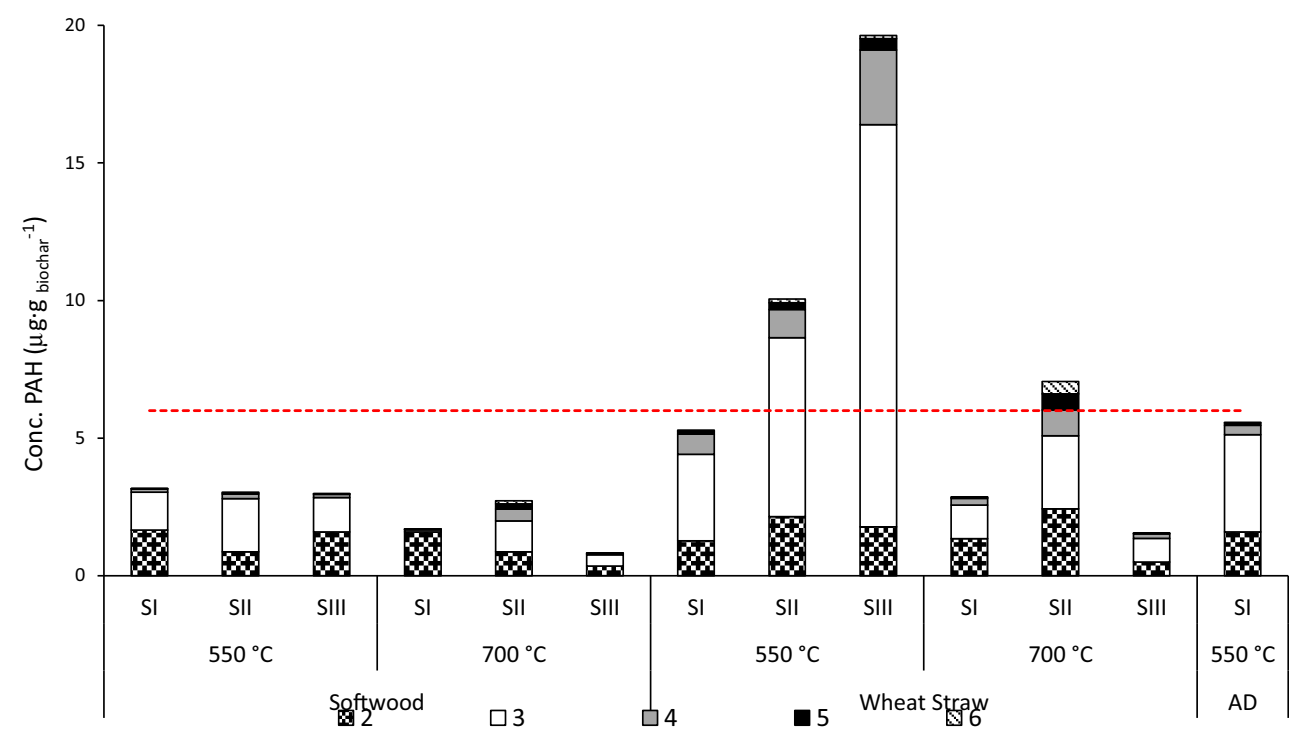

oxy-PAH concentrations are attributed to the composition of the digestate feedstock, which differs from those of the other two feedstocks.

The highest concentration (477 ng $\mathrm{g}_{\text {biochar }}{ }^{-1}$ ) of N-PACs occurred in wheat straw (rather than the anaerobic digestate) pyrolyzed at $550{ }^{\circ} \mathrm{C}$ (stage II), despite the anaerobic digestate having higher total $\mathrm{N}$ content than the wheat straw (Table 1). This possibly indicates that not total content, but actual $\mathrm{N}$ speciation (organic/inorganic) dictates the formation magnitude of the N-PAC species. Discussion on the toxicity of oxy-PAHs and N-PACs is ongoing, and therefore, threshold values for these compounds in biochar are lacking (Andersson and Achten 2015).

\section{Distribution of PAH, oxy-PAH, and N-PAC between biochar and the liquid fraction in stage I (SI)}

The liquid fraction, which was only collected from stage I (batch reactor, Table 2), constituted $44-49 \%$ of the total product yield of the pyrolysis process (Table 3 ). The distribution of $\mathrm{PAH}$, oxy-PAH, and N-PAC between the biochar and liquid fraction showed that these products occurred mainly in the liquid fraction. In Fig. 3, the concentrations of PAH and oxy-PAH is shown. For example, the PAH concentration of the liquid fraction ranged from 28.6 to $351 \mathrm{\mu g} \mathrm{g}^{-1}$ while the concentrations of biochar were 1.7 to $5.6 \mu \mathrm{g} \mathrm{g}^{-1}$, making the concentration in the liquid 5-140 times larger than in the char.
Fig. 2 Concentrations (plotted on different scales) of oxy-PAH (columns) and N-PAC (bullets) in biochar from the different pyrolysis units. SI-SIII: size of the pyrolysis equipment (stage I, stage II, and stage III, respectively) and AD: anaerobic digestate

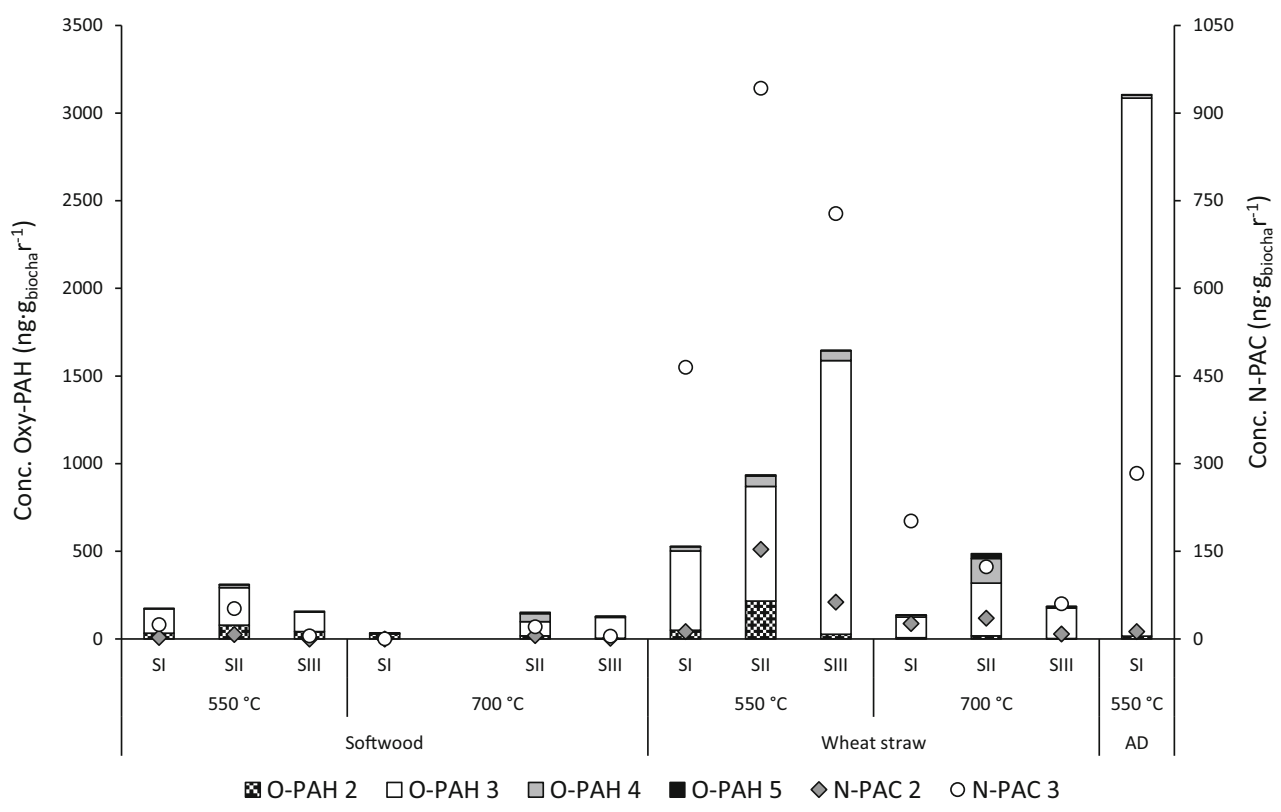


Fig. 3 Distribution of PAH, O$\mathrm{PAH}$, and N-PAC in char, and $\mathrm{PAH}$ and $\mathrm{O}-\mathrm{PAH}$ in the liquid fraction. N-PAC in the liquid fraction is not shown since the corresponding concentrations were below the limit of quantification (LOQ)

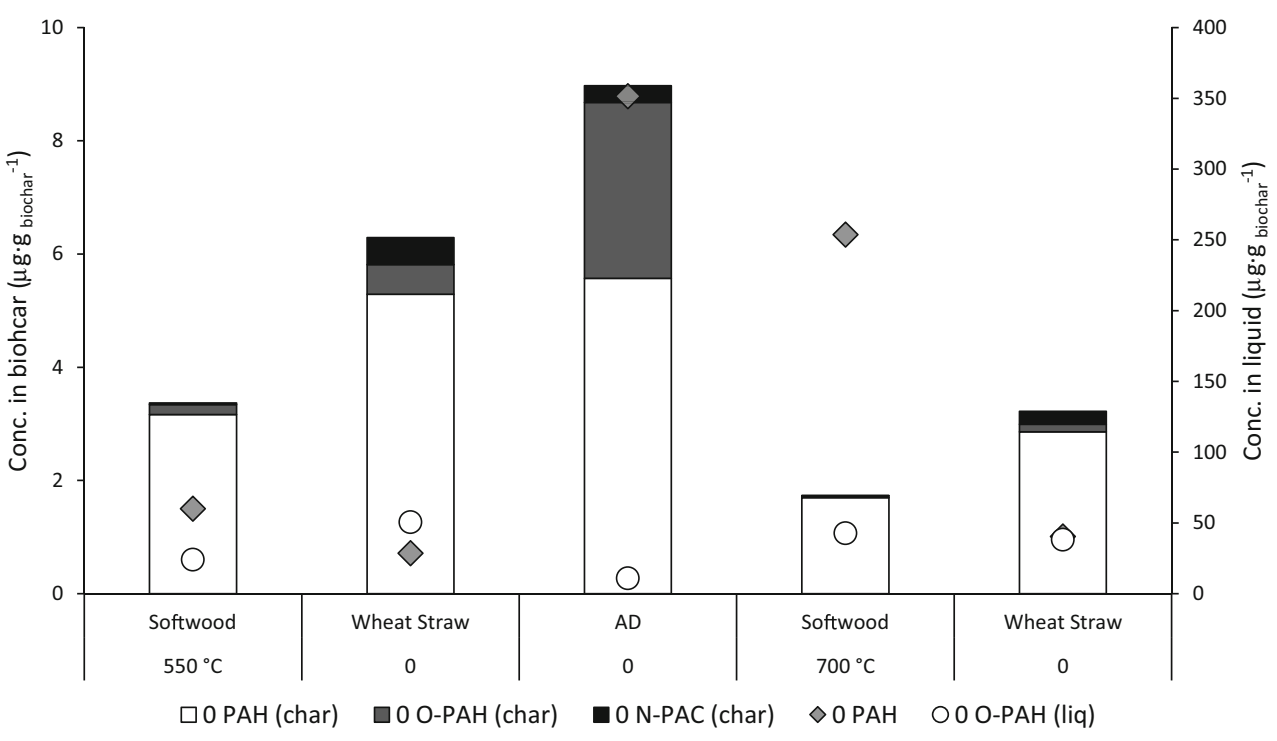

The distribution of the PAH and oxy-PAH in the liquid fraction tended to be lighter species, with less rings, compared to the char. All six-ringed PAHs in the liquid samples were below LOQ, N-PAC concentrations in the liquid fraction were compared to the PAH and oxy-PAH concentrations too low to be included in the Fig. 3, but except for wheat straw pyrolyzed at $550{ }^{\circ} \mathrm{C}, 80 \%$ or more of the total N-PAC were found in the liquid fraction. For the wheat straw sample, equal amounts were found in both liquid and char. Fagernäs et al. (2012) found that 62,37 , and only $0.6 \%$ of the PAHs occurred in the tars, gases, and the char, respectively. We did not measure the PAH concentration of the gases, but found that a considerably higher amount of PAHs occurred in the pyrolysis liquids than in the solids/char (PAH content of the solids: 0.39.3\%). This demonstrates that PAH separation from char, via evaporation, is very effective. However, to prevent PAH deposition onto the biochar, contact between pyrolysis vapors (liquids and gases) and char in the very cold sections of the pyrolysis unit must be avoided.

Regardless of the operating conditions during the softwood and wheat straw runs, the PAH, oxy-PAH, and N-PAC content of the biochars decreased with increasing pyrolysis temperature, whereas the PAH content of the liquid fraction increased. These results suggest that although pyrolysis at $700{ }^{\circ} \mathrm{C}$ yields more PAHs (than pyrolysis at $550{ }^{\circ} \mathrm{C}$ ), this process can generate biochars with lower levels of these potentially toxic compounds, as most PAHs evaporate from the char.

\section{Polychlorinated dibenzo-p-dioxins and furans}

Consistent with a previous study (Wiedner et al. 2013), the results from this screening study showed that extractable polychlorinated aromatics species occur at almost negligible levels in the biochar matrix. Some PCDDs and PCDFs in the biochar, although detectable, were non-quantifiable

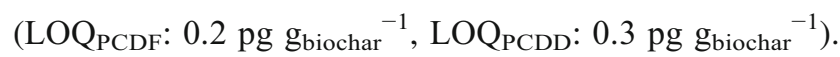
Monochlorinated dibenzofuran (MoCDF) was the only homolog that occurred with concentrations exceeding blank concentrations by some margin (defined as blank concentration times five), and this occurred in only 7 of the 13 biochars. Formation of MoCDF occurred more easily (and was therefore favored) at lower pyrolysis temperature and at larger pyrolysis unit (stage II and stage III) (data not shown), than at high pyrolysis temperatures and smaller scale. However, quantification of mono- to trichlorinated dioxins and furans in the liquid fraction was prevented by considerable matrix interference. Similarly, highly chlorinated congeners (hepta- and octachlorinated dioxins and furans) in the liquid fraction obtained from softwood and anaerobic digestate at $550{ }^{\circ} \mathrm{C}$ were non-quantifiable (LOQ 4 pg gbiochar $^{-1}$ ).

As the potential concentration of toxic PCDD and PCDF congeners in the biochars could not be calculated, approximate values were obtained by assigning to each congener a concentration equal to the LOQ values. Using this criterion, maximum concentrations of $0.6-0.9 \mathrm{pg}_{\mathrm{TEQ}} \mathrm{g}_{\text {biobiochar }}{ }^{-1}$, which are slightly higher than TEQ concentrations reported for biochars generated from slowly pyrolyzed biomass (Hale et al. 2012), are expected for the toxic components of the biochars. The estimated worst-case TEQ concentrations are lower than the PCDD and PCDF threshold (17 $\mathrm{pg}_{\mathrm{TEQ}} \mathrm{g}_{\text {biochar }}{ }^{-1}$ ) established by IBI for biochars that will be used as soil amendment (International Biochar Initiative 2015). As in the case of PAHs, regardless of the temperature, configuration, or size of the pyrolysis unit, the biochars are expected to have low environmental impact when used for soil-improvement purposes.

Using LOQ, concentrations yielded an estimated worstcase TEQ concentration of $\sim 1 \mathrm{pg}_{\mathrm{TEQ}} \mathrm{g}_{\text {biochar }}{ }^{-1}$ for the liquid fraction. 


\section{Conclusions}

The influence of temperature and type/size of the pyrolysis unit on the concentration of four groups of toxic contaminants was evaluated in biochars from three different biomass feedstocks representing three major types of biomass, namely: forestry and agricultural residues, and organic waste. The results revealed that the type of biomass has a significant influence on the concentration of PAH, oxy-PAH, and N-PAC; the configuration and type/size of the pyrolysis unit have a significant effect only on wheat straw pyrolyzed at $550{ }^{\circ} \mathrm{C}$.

This study represents the first-ever investigation where the content of oxy-PAH and N-PAC contaminants in biochars is determined. The results showed that in all cases this content is considerably lower than the PAH concentration. Regardless of the pyrolysis temperature, the PAH, oxy-PAH, and N-PAC concentrations were much higher in the liquid fraction compared to the char fractions. The PDCCs and PCDFs occurred at negligible levels in the studied biochars. Moreover, in terms of PAH, PCDD, and PCDF content, and regardless of the temperature and pyrolysis unit, the biochars are expected to have low negative environmental impact related to these contaminants when used for soil amendment. This demonstrates that biochar with extremely low content of organic pollutants can be produced from a range of materials and by using various technologies, which is an important milestone on the way to widespread biochar deployment and commercialization.

Acknowledgements The authors gratefully acknowledge Bio4Energy (www.bio4energy.se), a strategic research environment provided by the Swedish government, for supporting this work. We also thank Per Liljelind for his assistance with the GC-MS analyses.

Funding Part of the study was funded by grants from the Ångpanneföreningen's Foundation for Research and Development and the J. Gust. Richert Memorial Fund.

Open Access This article is distributed under the terms of the Creative Commons Attribution 4.0 International License (http:// creativecommons.org/licenses/by/4.0/), which permits unrestricted use, distribution, and reproduction in any medium, provided you give appropriate credit to the original author(s) and the source, provide a link to the Creative Commons license, and indicate if changes were made.

\section{References}

Andersson JT, Achten C (2015) Time to say goodbye to the 16 EPA PAHs? Toward an up-to-date use of PACs for environmental purposes. Polycyc Aromat Comp 35

Arp HPH, Lundstedt S, Josefsson S, Cornelissen G, Enell A, Allard A-S, Kleja DB (2014) Native oxy-PAHs, N-PACs, and PAHs in historically contaminated soils from Sweden, Belgium, and France: their soil-porewater partitioning behavior, bioaccumulation in Enchytraeus crypticus, and bioavailability. Environ Sci Technol 48:11187-11195
Bacher R, Swerev M, Ballschmiter K (1992) Profile and pattern of monochloro- through octachlorodibenzodioxins and dibenzofurans in chimney deposits from wood burning. Environ Sci Technol 26:1649-1655

Baker EG, Elliott DC (1986) Catalytic hydrotreating of biomass-derived oils. Pacific Northwest Lab, Richland, WA

British Biochar Foundation (2014) Biochar quality mandate Version:1.0

Britt PF, Buchanan AC, Owens Jr CV, Skeen JT (2002) Formation of nitrogen containing polycyclic aromatic compounds from the $\mathrm{CO}-$ pyrolysis of carbohydrates and amino acids. In: ACS division of fuel chemistry, preprints, pp 400-403

Buss W, Graham MC, MacKinnon G, Mašek O (2016a) Strategies for producing biochars with minimum PAH contamination. J Anal Appl Pyrol 119:24-30

Buss W, Graham MC, Shepherd JG, Mašek O (2016b) Suitability of marginal biomass-derived biochars for soil amendment. Sci Total Environ 547:314-322

Buss W, Mašek O (2014) Mobile organic compounds in biochar-a potential source of contamination - phytotoxic effects on cress seed (Lepidium sativum) germination. J Environ Manag 137:111-119

Crombie K, Mašek O, Sohi SP, Brownsort P, Cross A (2013) The effect of pyrolysisconditions on biochar stability as determined by three methods. GCB Bioenergy 5:122-131

Devi P, Saroha AK (2015) Effect of pyrolysis temperature on polycyclic aromatic hydrocarbons toxicity and sorption behaviour of biochars prepared by pyrolysis of paper mill effluent treatment plant sludge. Bioresour Technol 192:312-320

Elliott DC (1986) Analysis and comparison of biomass pyrolysis/ gasification condensates: final report, in: Pacific Northwest Lab., Richland, WA (USA), Medium: ED; Size: Pages: 100

European Biochar Foundation (2016) European biochar certificateguidelines for a sustainable production of biochar, in: http://www. europeanbiochar.org/en/download

Fagernäs L, Kuoppala E, Simell P (2012) Polycyclic aromatic hydrocarbons in birch wood slow pyrolysis products. Energ Fuel 26:6960 6970

Freddo A, Cai C, Reid BJ (2012) Environmental contextualisation of potential toxic elements and polycyclic aromatic hydrocarbons in biochar. Environ Pollut 171:18-24

Fullana A, Conesa JA, Font R, Martín-Gullón I (2003) Pyrolysis of sewage sludge: nitrogenated compounds and pretreatment effects. J Anal Appl Pyrolysis 68:561-575

Gao Q, Haglund P, Pommer L, Jansson S (2015) Evaluation of solvent for pressurized liquid extraction of PCDD, PCDF, PCN, PCBz, PCPh and PAH in torrefied woody biomass. Fuel 154:52-58

Hajizadeh Y, Onwudili JA, Williams PT (2011) PCDD/F formation from oxy-PAH precursors in waste incinerator flyash. Chemosphere 85: $1672-1681$

Hale SE, Lehmann J, Rutherford D, Zimmerman AR, Bachmann RT, Shitumbanuma V, O'Toole A, Sundqvist KL, Arp HPH, Cornelissen G (2012) Quantifying the total and bioavailable polycyclic aromatic hydrocarbons and dioxins in biochars. Environ Sci Technol 46:2830-2838

International Biochar Initiative (2015) Standardized product definition and product testing guidelines for biochar that is used in soil Version:2.1

Keiluweit M, Kleber M, Sparrow MA, Simoneit BRT, Prahl FG (2012) Solvent-extractable polycyclic aromatic hydrocarbons in biochar: influence of pyrolysis temperature and feedstock. Environ Sci Technol 46:9333-9341

Kloss S, Zehetner F, Dellantonio A, Hamid R, Ottner F, Liedtke V, Schwanninger M, Gerzabek MH, Soja G (2012) Characterization of slow pyrolysis biochars: effects of feedstocks and pyrolysis temperature on biochar properties. J Environ Qual 41:990-1000

Lehmann JJ, Joseph S (2009) Biochar for environmental management: science and technology 
Liljelind P, Söderström G, Hedman B, Karlsson S, Lundin L, Marklund S (2003) Method for multiresidue determination of halogenated aromatics and PAHs in combustion-related samples. Environ Sci Technol 37:3680-3686

Lundstedt S, Haglund P, Öberg L (2003) Degradation and formation of polycyclic aromatic compounds during bioslurry treatment of an aged gasworks soil. Environ Toxicol Chem 22:1413-1420

Mohan D, Pittman CU, Steele PJ (2006) Pyrolysis of wood/biomass for bio-oil: a critical review. Energ Fuel 20:848-889

Nielsen T, Feilberg A, Binderup ML (1999) The variation of street air levels of PAH and other mutagenic PAC in relation to regulations of traffic emissions and the impact of atmospheric processes. Environ Sci Pollut Res 6:133-137

Pakdel H, Roy C (1991) Hydrocarbon content of liquid products and tar from pyrolysis and gasification of wood. Energ Fuel 5:427-436

Ryan JJ, Conacher HBS, Panopio LG, Lau BPY, Hardy JA, Masuda Y (1991) Gas chromatographic separations of all 136 tetra- to octapolychlorinated dibenzo-p-dioxins and polychlorinated dibenzofurans on nine different stationary phases. J Chromatogr A 541: $131-183$

US EPA (2015) Code of federal regulations, Appendix A to 40 CFR, part 423, Priority pollutants, in: U.S. EPA
Van den Berg M, Birnbaum LS, Denison M, De Vito M, Farland W, Feeley M, Fiedler H, Hakansson H, Hanberg A, Haws L, Rose M, Safe S, Schrenk D, Tohyama C, Tritscher A, Tuomisto J, Tysklind M, Walker N, Peterson RE (2006) The 2005 World Health Organization reevaluation of human and mammalian toxic equivalency factors for dioxins and dioxin-like compounds. Toxicol Sci 93: 223-241

Weber R, Lino F, Imagawa T, Takeuchi M, Sakurai T, Sadakata M (2001) Formation of PCDF, PCDD, PCB, and PCN in de novo synthesis from PAH: mechanistic aspects and correlation to fluidized bed incinerators. Chemosphere 44:1429-1438

Wiedner K, Rumpel C, Steiner C, Pozzi A, Maas R, Glaser B (2013) Chemical evaluation of chars produced by thermochemical conversion (gasification, pyrolysis and hydrothermal carbonization) of agro-industrial biomass on a commercial scale. Biomass Bioenergy 59:264-278

Wolfesberger U, Aigner I, Hofbauer H (2009) Tar content and composition in producer gas of fluidized bed gasification of wood-influence of temperature and pressure. Environ Prog Sustain Energy 28:372379

Zhao L, Cao X, Mašek O, Zimmerman A (2013) Heterogeneity of biochar properties as a function of feedstock sources and production temperatures. J Hazard Mater 256-257:1-9 